\title{
Health and Safety among open - pit mining industry: Current situation and recommendations
}

\author{
Tho Anh Nguyen 1,*, Bich Ngoc Nguyen ${ }^{2}$ \\ ${ }^{1}$ Administration of Occupational Safety - Ministry of Labour - Invalid and Social Welfare, Vietnam \\ ${ }^{2}$ Faculty of Environmental and Occupational Health, Hanoi University of Public Health, Vietnam
}

\section{ARTICLE INFO}

Article history:

Received 18th Aug. 2020

Revised 22nd Sep. 2020

Accepted $10^{\text {th }}$ Oct. 2020

\section{Keywords:}

Health,

Occupational safety,

Open pit mining industry.

\section{ABSTRACT}

Mining industry has long development history and is among the most developed industry contributed to the economy of the country. Working in the sector is also considered as heavy and hazardous duty. The Law on Occupational Safety and Hygiene was passed and enacted in 2016, and different sub - law guiding documents were developed to regulate about working environment and risk control solution required for all industries especially for risky industry like mining. However, implementation and enforcement of Law was still inadequte. This review report aims to discuss about current situation of health and safety issues among the sector and to propose some possible solutions. Reults show that number of accidents and number of deaths was increasing. Prevalence of silicosis and hearing imparement among workers in the sector was among top ranking industries. It was recommended that monitoring, supervision and enforcement should be invested properly. Different technologies and innovations should also be applied on reducing the risk of occupational injury and diseases.

\footnotetext{
${ }^{*}$ Corresponding author

E-mail: anhthomolisa@gmail.com
}

DOI: 10.46326/JMES.KTLT2020.12 
Tạp chí Khoa học Kỹ thuật Mỏ - Địa chất

Trang điện tử: http://tapchi.humg.edu.vn

\title{
Sức khoẻ, an toàn nghề nghiệp trong khai thác khoáng sản: Tổng quan thực trạng và khuyến nghị
}

\author{
Nguyễn Anh Thơ ${ }^{1,}{ }^{*}$, Nguyễn Ngọc Bích ${ }^{2}$ \\ ${ }^{1}$ Cuc An toàn lao động, Bộ lao động - Thương binh - Xã hội, Việt Nam. \\ ${ }^{2}$ Khoa Sức khoẻ môi trường và nghề nghiệp, Trường Đại học Y tế công cộng, Việt Nam, Email: \\ nnb@huph.edu.vn
}

THÔNG TIN BÀI BÁO T TÓM TẮT

Quá trình:

Nhận bài $18 / 08 / 2020$

Sửa xong 22/09/2020

Chấp nhận đăng 10/10/2020

Tù̀ khóa:

An toàn nghề nghiệp;

Khai thác lộ thiên;

Sức khoẻ.
Khai thác khoáng sản là ngành có lịch sử lâu đầu và đang phát triển mạnh mẽ. Đây cũng là một ngành được xếp vào nhóm ngành nghề nặng nhọc, độc hại. Mặc dù Luật An toàn, vệ sinh lao đông (ATVSLĐ) có hiệu lực năm 2016 và các văn bản quy pham pháp luật đãa quy định chi tiết về điều kiện môi trường làm việc, yêu cẩu đảm bảo sức khoẻ, an toàn nghề nghiệp cho các ngành nghề, đặc biệt là khai thác khoáng sản, tuy nhiên thực trạng triển khai còn nhiều vấn đề. Báo cáo rà soát tổng quan với mục tiêu mô tả thực trạng các vấn đề sức khoẻ, an toàn nghề nghiệp trong ngành khai thác khoáng sản, và đề xuất các khuyến nghi. Kết quả cho thấy số vu tai nan lao động và số người chết không giảm qua các năm, Tỷ lệ mắc bệnh nghề nghiệp nhu bệnh bụi phổi silic, điếc nghề nghiệp vẫn cao và thuộc nhóm ngành nghề có tỷ lệ mắc cao nhất. Viẹc kiểm tra, giám sát, thực thi quy định cần được thực hiện nghiêm bởi các bộ, ngành cũng như tại các doanh nghiệp, áp dụng khoa học công nghệ để đảm bảo an toàn và điều kiện môi trường lao động, chăm sóc, bảo vệ người lao động phòng chống bệnh nghề nghiệp.

(C) 2020 Trường Đại học Mỏ - Địa chất. Tất cả các quyền được bảo đảm.

\section{Mở đầu}

Hoạt động khai thác khoáng sản thời gian qua đã và đang phát triển mạnh mẽ, tạo thêm nhiều việc làm, góp phần cải tạo từng bước cơ sở hạ tầng của các địa phương nơi có các mỏ khoáng sản,

\section{*Tác giả liên hệ}

E-mail: anhthomolisa@gmail.com

DOI: 10.46326/JMES.KTLT2020.12 nhất là ở những vùng sâu, vùng xa; đóng góp một phần không nhỏ cho sự phát triển của đất nước. Để quản lý chặt chẽ nguồn tài nguyên khoáng sản và quan trọng là bảo vệ tính mạng, sức khỏe người lao động và những quyền lợi chính đáng của người lao động trong khai thác mỏ và vấn đề sức khỏe, an toàn, vệ sinh lao động cho người lao động luôn là những ưu tiên hàng đầu. Trong nhưng năm gần đây, sau khi Luật ATVSLĐ (năm 2015, có hiệu lực từ tháng 7/2016) cùng với các Luật khoáng sản, 
Luật bảo vệ môi trường, Luật Bảo vệ chăm sóc sức khoẻ nhân dân và các văn bản quy phạm pháp luật, các Quy chuẩn kỹ thuật an toàn trong khai thác mỏ, vật liệu nổ công nghiệp được ban hành, trật tự khai thác khoáng sản, bảo vệ tài nguyên khoáng sản đã từng bước được thiết lập, hạn chế dần các hoạt động khai thác trái phép khoáng sản, khai thác gây mất ATVSLĐ, phá hoại môi trường. Tuy nhiên, tình hình vi phạm những quy định pháp luật về lao động, bảo hiểm xã hội, ATVSLĐ vẫn đang diễn ra phổ biến trong các doanh nghiệp, cơ sở khai thác khoáng sản; đặc biệt là tai nạn lao động trong khai thác mỏ, nhất là trong khai thác đá và một số loại khoáng sản khác đã và đang xảy ra rất nghiêm trọng, do sạt lở tầng khai thác, trụt lở bãi thải, sử dụng vật liệu nổ không an toàn.... đã làm chết và bị thương nặng nhiều người. Môi trường lao động trong hoạt động khai thác khoáng sản cũng đang bị ô nhiễm nghiêm trọng, làm nhiều người bị bệnh nghề nghiệp, đặc biệt là bệnh bụi phổi than nghề nghiệp, bụi phổi silic, điếc nghề nghiệp do tiếng ồn. Môi trường đó không chỉ ảnh hưởng trong phạm vi mỏ mà còn đang tác động không nhỏ đến một bộ phận rất lớn người dân sinh sống trong khu vực. Chính vì những lý do đó, việc bảo đảm các quyền lợi chính đáng của người lao động về tiền lương, bảo hiểm xã hội, điều kiện lao động, ATVSLĐ, bảo vệ môi trường trong khai thác mỏ lộ thiên đang rất cần sự quan tâm đầu tư và ý thức trách nhiệm của các doanh nghiệp, người lao động và các cơ quan, tổ chức liên quan.

Nghiên cứu này được thực hiện dựa trên Báo cáo tổng hợp các kết quả theo dõi tình hình sức khoẻ và an toàn nghề nghiệp trong ngành khai thác khoáng sản thế giới và Việt Nam.

\section{2. Đánh giá thực trạng sức khoẻ, an toàn nghề nghiệp trong khai thác khoáng sản}

\subsection{Các yếu tố nguy cơ an toàn và sức khoẻ trong khai thác khoáng sản}

Khai thác khoáng sản được xếp vào nhóm các ngành nghề nặng nhọc, độc hại. Trong môi trường làm việc của ngành khai thác khoáng sản lộ thiên hay dưới hầm lò, hoặc trong các dây chuyền chế biến, các yếu tố nguy cơ nghề nghiệp gây bệnh nghề nghiệp và các chấn thương nghề nghiệp đã được khẳng định qua các nghiên cứu (Jeyaratnam, J., 1992; Bateman, C., 2014; Nelson, G. và nnk., 2010; Naidoo, RN. và nnk., 2005; B. M. Kunar, 2015):

- Tiếng ồn;

- Bụi (silic, bụi than);

- Hơi khí độc;

- Hoá chất độc hại;

- Động tác lặp đi lặp lại;

- Rung cục bộ và rung toàn thân;

- Tư thế gò bó;

- Nhiệt độ quá nóng hoặc quá lạnh;

- Độ ẩm cao.

Ở Việt Nam, số liệu báo cáo và tổng hợp nghiên cứu cho thấy, ba trong số các yếu tố tác hại nghề nghiệp phổ biến nhất bao gồm (Bộ Y tế, 2018):

- Tiếng ồn (thường vượt quá tiêu chuẩn cho phép từ $10 \div 18 \mathrm{dBA}$ ), cao nhất ở các phân xưởng nghiền sàng

- Bụi (cao gấp 15 - 30 lần so với tiêu chuẩn cho phép), phổ biến là bụi si lic

- Rung cục bộ do sử dụng máy khoan và rung toàn thân do lái xe chuyên dụng.

\subsection{Thực trạng an toàn lao động}

Một nghiên cứu tổng quan hệ thống cho thấy trong ngành khai thác khoáng sản, các chấn thương cơ xương khớp (tay, lưng, chân, rách da, tổn thương cơ), trượt, ngã là các chấn thương phổ biến nhất (Nowrouzi-Kia B. và nnk., 2018).

Nghiên cứu tại Zimbabwe về các yếu tố liên quan với chấn thương nặng cho thấy các nguyên nhân phổ biến liên quan đến chấn thương nặng là (Chimamise C. và nnk., 2010; Yan C. và nnk., 2015):

- Làm việc dưới hầm lò $(\mathrm{AOR}=10,55$; CI $5,97 \div 18,65)$; 
- Giao khoán việc trong ca làm việc $(\mathrm{AOR}=$ 12,60; CI 3,46 $\div 45,84$ );

- Trang bị phòng hộ cá nhân không phù hợp $(\mathrm{AOR}=3,65 \mathrm{CI} 1,34 \div 9,89)$;

- Làm việc quá 8 tiếng trong một ca làm việc (AOR $=8,65$ CI $2,99 \div 25,02)$.

Ở Việt Nam, riêng trong khai thác mỏ, tình hình tai nạn lao động, nhất là trong khai thác than, khai thác đá và một số loại khoáng sản khác đã và đang xảy ra rất nghiêm trọng, do sạt lở tầng khai thác, sạt lở bãi thải... ở mỏ lộ thiên, làm chết và bị thương nặng nhiều người. Theo thống kê của Bộ Lao động - Thương binh và Xã hội, tai nạn lao động và tai nạn lao động chết người trong khai thác khoáng sản trong những năm gần gây luôn chiếm tỷ lệ cao, khoảng trên dưới 20\% tổng số vụ tai nạn lao động và có hàng ngàn người bị bệnh nghề nghiệp. Tình hình tai nạn lao động, bệnh nghề nghiệp trong những năm qua diễn biến vẫn còn rất phức tạp. Trong giai đoạn 2010-2016, số người chết và số người bị nan tăng, số vụ tai nạn lao động nghiêm trọng cũng đã xảy ra có chiều hướng tăng và mức độ rất nghiêm trọng, có nhiều người chết trong một vụ. Trong giai đoạn 2017-2019, số vụ TNLĐ chết người đặc biệt nghiêm trọng đã được kiểm chế (Bộ Lao động - Thương binh và Xã hội, 2019a).

Trong Tập đoàn Công nghiệp Than - Khoáng sản Việt Nam, giai đoạn 2013-2019, số vụ sự cố TNLĐ và số người chết do TNLĐ đã giảm nhiều: tỷ lệ số người chết/1 triệu tấn than đã giảm từ 0,7 người/1 Tr.t (năm 2013) xuống 0,43 người/1 Tr.t (năm 2018), nhưng vẫn chưa đạt được mục tiêu đề ra (mục tiêu phấn đấu giảm số người chết hàng năm về một con số và tiến tới tai nạn chết người bằng không). Số vụ TNLĐ chết người cũng như số người chết do TNLĐ trong Tập đoàn Công nghiệp Than - Khoáng sản Việt Nam từ năm 2013 đến 06/2020 được tổng hợp trong Bảng 1 (Bộ Lao động - Thương binh và xã hội, 2019b).

Tai nạn lao động trong khai thác mỏ lộ thiên cũng khá phổ biến. Nghiêm trọng nhất vẫn là tình trạng tai nạn lao động trong khai thác đá. Điển hình là một số vụ tai nạn lao động vào cuối năm 2007 và đầu năm 2008, 2011. Ví dụ vụ tai nạn làm chết 18 người tại Bản Vẽ - Nghệ An, vụ tai nạn làm chết 07 người và bị thương nhiều người tại mỏ đá Rú mốc, Hà Tĩnh và các vụ tai nạn tại các mỏ đá Thống Nhất, Hà Nam và mỏ đá Hóc Trùm, xã Hòa Xuân Tây, Đông Hòa, Phú yên. Gần đây nhất là vụ tai nạn làm chết 18 người và 6 người bị thương tại mỏ đá Lèn Cờ - Huyện Yên Thành, Nghệ An vào ngày 01 tháng 4 năm 2011.

Bảng 1. Tai nạn lao động chết người trong Tập đoàn Công nghiệp Than - Khoáng sản Việt Nam liên quan đến khai thác khoáng sản

\begin{tabular}{|c|c|c|c|}
\hline Năm & $\begin{array}{c}\text { Kinh phí chi } \\
\text { cho ATVSLĐ } \\
\text { (Tỷ đồng) }\end{array}$ & $\begin{array}{c}\text { Số vụ } \\
\text { TNLĐ } \\
\text { chết } \\
\text { người }\end{array}$ & $\begin{array}{c}\text { Số } \\
\text { người } \\
\text { chết do } \\
\text { TNLĐ }\end{array}$ \\
\hline 2013 & 994,3 & 26 & 30 \\
\hline 2014 & $1.016,8$ & 22 & 27 \\
\hline 2015 & 923,2 & 17 & 20 \\
\hline 2016 & 1.032 & 22 & 25 \\
\hline 2017 & 985,2 & 15 & 16 \\
\hline 2018 & $1.067,2$ & 17 & 17 \\
\hline 2019 & 1132 & 13 & 14 \\
\hline $6 / 2020$ & - & 07 & 07 \\
\hline
\end{tabular}

\subsection{Thực trạng sức khoẻ nghề nghiệp}

Khám Bệnh nghề nghiệp (BNN): danh mục bệnh nghề nghiệp được hưởng bảo hiểm xã hội là 34 bệnh. Năm 2018 có 30 tỉnh/thành phố có báo cáo tình hình khám phát hiện cho 31/34 loại bệnh nghề nghiệp. Trong 5 năm từ 2014-2018, số trường hợp mắc BNN đã giảm $53 \%$ so với giai đoạn 2006-2010. Bệnh bụi phổi silic giảm 78\%, Bệnh nhiễm độc TNT giảm 47\%, tuy nhiên bệnh điếc do tiếng ồn tăng $38 \%$ và Bệnh viêm gan virut nghề nghiệp tăng 98\%. Trung bình mỗi năm có khoảng $100 \div 200$ ngàn người lao động được khám phát hiện bệnh nghề nghiệp và trên 5000 trường hợp mắc bệnh nghề nghiệp được phát hiện (chiếm khoảng 5\%), số người lao động được giám định chỉ chiếm khoảng 10\% tổng số mắc (Hình 1). 


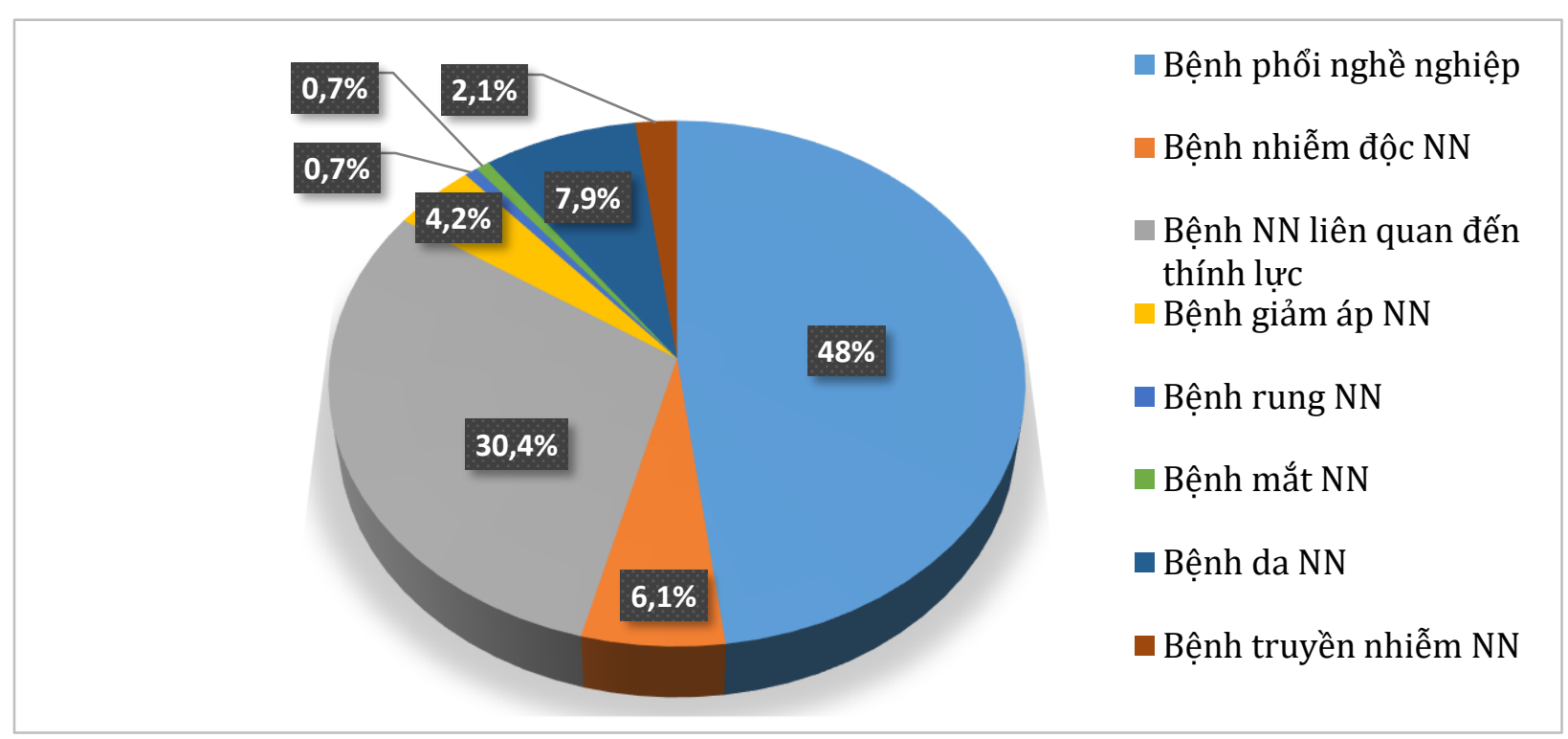

Hình 1. Tình hình khám bệnh nghề nghiệp cho người lao động năm 2018

Thống kê sơ bộ cho thấy giai đoạn 2016-2018, đã có khoảng 769.286 người lao động được khám phát hiện BNN, kết quả thực hiện năm sau có xu hướng tăng so với năm trước. Riêng trong năm 2018 đã có 316.636 trường hợp (tăng 7,25\% so với năm trước) được khám phát hiện $B N N$, trong đó đã phát hiện được 10.157 trường hợp mắc bệnh (chiếm tỷ lệ 3,2\%). Số người được giám định năm 2018 cũng tăng 6,7\% (năm 2018 có 838 trường hợp được giám định) so với 2017 và tăng gấp hơn 3 lần so với năm 2016.

Giai đoạn 2016-2018, mặc dù số người mắc mới BNN tăng ít qua các năm nhưng số người mắc BNN vẫn ở mức cao. Số mắc BNN cộng dồn đến năm 2018 là 29.725 trường hợp. Kết quả khám phát hiện BNN cho thấy 03 loại BNN có số mắc bệnh cao nhất là bệnh bụi phổi silic, bệnh điếc nghề nghiệp và bệnh da nghề nghiệp. So sánh với giai đoạn trước cho thấy một số BNN có tỷ lệ mắc giảm nhanh , tuy nhiên cũng có một số nhóm bệnh có chiều hướng tăng rất nhanh (bệnh điếc do tiếng ồn tăng 38\% và bệnh viêm gan virut nghề nghiệp tăng 98\%). Về lĩnh vực, khai khoáng, vật liệu xây dựng, cơ khí, sản xuất và sử dụng hóa chất là các ngành nghề có tỷ lệ mắc BNN cao nhất.

Năm 2018, có 42 tỉnh/thành phố thực hiện khám phát hiện được 34/34 loại bệnh nghề nghiệp. Có 4 bệnh nghề nghiệp mới được tổ chức khám trong năm 2018 là: bệnh nhiễm độc mangan nghề nghiệp, bệnh nhiễm độc Asen nghề nghiệp, bệnh nhiễm độc Cadimi nghề nghiệp và bệnh ung thư trung biểu mô nghề nghiệp.

Tổng số người lao động tiếp xúc với yếu tố có hại được thực hiện khám phát hiện bệnh nghề nghiệp là 316.636 trường hợp (tăng 7,2\% so với cùng kỳ năm 2017), trong đó đã phát hiện được 3.535 trường hợp mắc bệnh nghề ng hiệp (chiếm 1,1\% tổng số khám), trong đó một số bệnh nghề nghiệp có tỷ lệ mắc cao như: bệnh điếc nghề nghiệp do tiếng ồn $(66,6 \%)$, bệnh bụi phổi silic nghề nghiệp $(16,8 \%)$, bệnh bụi phổi than nghề nghiệp $(9,9 \%)$, bệnh viêm phế quản mạn tính nghề nghiệp (2\%).

Tích luỹ số trường hợp mắc BNN được hưởng bảo hiểm đến hết năm 2018 là 29.725 trường hợp. 03 BNN có số mắc cao nhất bao gồm: bệnh bụi phổi silic $(72,18 \%)$; bệnh điếc nghề nghiệp $(17,84 \%)$ và bệnh da nghề nghiệp $(2,18 \%)$. Khai khoáng, vật liệu xây dựng, cơ khí, sản xuất và sử dụng hóa chất là các ngành nghề có tỷ lệ mắc bệnh nghề nghiệp cao nhất. Ngoài ra, hiện nay đã ghi nhận 193 trường hợp được chẩn đoán ung thư trung biểu mô trong giai đoạn 1987-2017 (theo số liệu báo cáo của 9 Trung tâm ghi nhận ung thư trong toàn quốc).

Công tác chăm sóc sức khỏe người lao động đối với khu vực lao động không có hợp đồng lao động chưa được quy định cụ thể: do không có hợp đồng 
lao động, không được đóng bảo hiểm xã hội và bảo hiểm y tế nên đa số người lao động phi chính thức không được hưởng các chế độ bảo trợ xã hội và các chế độ việc làm khác như khám tuyển dụng, theo dõi sức khỏe định kỳ, khám chẩn đoán bệnh nghề nghiệp, chế độ bồi dưỡng khi làm các công việc nặng nhọc, độc hại, nguy hiểm,... đặc biệt là rất hạn chế về tiếp cận các dịch vụ y tế lao động cơ bản.

\section{Nguyên nhân và thách thức về an toàn, sức khỏe nghề nghiệp trong khai thác lộ thiên}

\subsection{Nguyên nhân}

Thực tế hiện nay, trừ các mỏ khai thác than và một số mỏ khai thác đá làm nguyên liệu sản xuất xi măng được đầu tư quy mô, tổ chức khai thác mỏ tuân thủ đầy đủ các quy định, quy chuẩn kỹ thuật an toàn khai thác mỏ từ khâu khai thác, vận chuyển đến chế biến, còn lại phần lớn các mỏ đá hiện nay ở các địa phương, đặc biệt là những mỏ đá được ủy ban Nhân dân tỉnh cấp phép có quy mô khai thác nhỏ, không quá 100.000 m3/năm với thời gian khai thác có khi không quá 5 năm. Tại những mỏ này, tình trạng phổ biến là không tiến hành thăm dò khoáng sản, không có thiết kế mỏ và nếu có thì cũng không được cơ quan có thẩm quyền thẩm định theo quy định. Biện pháp khai thác chủ yếu tại các mỏ là khấu suốt, chiều cao tầng khai thác và góc dốc sườn tầng khai thác không đáp ứng các quy định về an toàn trong khai thác. Các mỏ thường không có giám đốc điều hành mỏ đảm bảo đủ điều kiện năng lực chuyên môn cũng như năng lực quản lý, điều hành mỏ theo quy định hiện hành.

Trong khai thác than, nguyên nhân chủ yếu của các vụ tai nạn lao động là do ý thức, nhận thức của cả người sử dụng và người lao động chưa đáp ứngyêu cầu. Người sử dụng lao động, cán bộ quản lý, giám sát thiếu chặt chẽ, chất lượng thấp; người lao động thiếu tác phong công nghiệp, vi phạm quy trình, quy phạm. Thiết kế thi công khai thác còn thiếu các biện pháp an toàn lao động cụ thể, cán bộ chỉ đao sản xuất và giám sát an toàn thiếu kỹ năng đáng giá rủi ro và đề ra các biện pháp an toàn cho từng ca sản xuất, khu vực sản xuất. Nhiều vụ tai nạn lao động chưa được thống kê, phân tích nguyên nhân và đề ra các biện pháp phòng ngừa cụ thể; hiệu quả của công tác kiểm tra, thanh tra thấp và xử lý vi phạm chưa nghiêm.

\subsection{Thách thức}

Từ thực trạng và tồn tại trong công tác an toàn, vệ sinh lao động như đã nêu trên, trong hoạt động khai thác mỏ thời gian tới sẽ vẫn tồn tại những thách thức và nguy cơ gây mất an toàn lao động, bệnh nghề nghiệp cần sớm có những giải pháp đồng bộ để khắc phục. Những thách thức đó là: (i) Điều kiện khai thác các mỏ hầm lò ngày càng khó khăn do phải xuống sâu, điều kiện địa chất ngày càng phức tạp, nguy cơ bục nước, khí mỏ tăng; (ii) Chuyển nhanh từ khai thác lộ thiên sang khai thác hầm lò; yêu cầu về sản lượng khai thác ngày càng tăng nhanh để đáp ứng yêu cầu của nền kinh tế.

Môi trường lao động trong hoạt động khai thác khoáng sản cũng đang bị ô nhiễm nghiêm trọng, làm nhiều người bị bệnh nghề nghiệp, đặc biệt là bệnh bụi phổi nghề nghiệp. Môi trường đó không chỉ ảnh hưởng trong phạm vi mỏ mà còn đang tác động không nhỏ đến một bộ phận rất lớn người dân sinh sống trong khu vực. Chính vì những lý do đó, việc bảo đảm an toàn, vệ sinh lao động, bảo vệ môi trường trong khai thác mỏ đang rất cần sự quan tâm đầu tư và ý thức trách nhiệm của các doanh nghiệp, người lao động và các cơ quan, tổ chức liên quan.

\section{Một số khuyến nghị trong hoạt động phòng ngừa tai nạn lao động, bệnh nghề nghiệp trong ngành mỏ}

\subsection{Tăng cường công tác tuyên truyền}

Các công ty mỏ cần chủ động đổi mới tuyên truyền thông qua các hoạt động trình diễn cháy nổ khí, trình chiếu hình ảnh về an toàn tại mặt bằng khai trường sản xuất; triển khai ký cam kết thực 
hiện công tác ATVSLĐ; tổ chức sinh hoạt chi bộ chuyên đề về công tác an toàn; treo, dán các loại tranh, ảnh, pa nô, áp phích, khẩu hiệu tuyên truyền về công tác ATVSLĐ tại những nơi làm việc, nơi đông người tại các nhà giao ca, bến xe và trên xe ô tô chở công nhân; tuyên truyền về ATVSLĐ dưới hình thức sân khấu hóa; tăng cường lắp đặt các biển chỉ dẫn trong hầm lò, các biển cảnh báo nguy hiểm ở những vị trí có nguy cơ mất an toàn, kể cả trên máy móc, thiết bị... Duy trì các buổi phát thanh chuyên đề về công tác an toàn trên phương tiện truyền thanh nội bộ đến tận các nhà giao ca, nơi tập trung đông người và vào tận trong hầm lò. Kịp thời phổ biến đến người lao động những thông tin liên quan đến các vụ tai nạn, sự cố đã xảy ra tại các đơn vị, để người lao động rút kinh nghiệm trong quá trình làm việc.

\subsection{Tăng cường đào tạo kỹ năng phòng tránh rủi ro, tai nạn lao động}

Công tác phát triển nguồn nhân lực cần được các công ty mỏ quan tâm từ khâu tuyển dụng, đào tạo, đến bố trí sắp xếp công việc.

Cần thực hiện công tác huấn luyện ATVSLĐ cho người lao động theo quy định của Luật ATVSLĐ số 84/2015, Nghị định số 44/2016/NĐ-CP, Thông tư số 31/2014/TT-BCT và thực hiện việc huấn luyện công nghệ, biện pháp thi công, huấn luyện an toàn theo 3 bước cho công nhân mới lập kế hoạch và tổ chức diễn tập về ứng cứu sự cố, tìm kiếm cứu nạn, phòng chống cháy nổ theo quy định. Cần phải tổ chức các lớp bồi dưỡng về kiến thức chuyên môn, kỹ năng làm việc cho cán bộ kỹ thuật, cán bộ chỉ huy sản xuất; tổ chức kiểm tra sát hạch lại kiến thức, tay nghề cho công nhân làm việc có yêu cầu nghiêm ngặt về an toàn lao động để nâng cao kỹ năng trong quá trình thực hiện công việc.

Các công ty mỏ phải thực hiện kế hoạch đánh giá rủi ro; xây dựng chương trình tự chủ an toàn ở các đơn vị thành viên, trên cơ sở: người quản lý phải tạo môi trường làm việc an toàn cho người lao động và kiểm soát cấp dưới tuân thủ các quy định về an toàn lao động; nơi nào không đảm bảo an toàn không được đưa công nhân vào làm việc; người chỉ đạo trực tiếp và người lao động biết dự báo nguy cơ mất an toàn trước khi làm việc, biết tự bảo vệ mình, bảo vệ đồng đội, không hiểu thì hỏi, không biết không làm, tuân thủ nghiêm túc các nội quy, quy định an toàn.

\subsection{Tăng cường úng dụng khoa học - công nghệ trong sản xuất}

Các công ty mỏ cần tăng cường đầu tư công nghệ mới cho sản xuất, đầu tư trang bị thiết bị an toàn tiên tiến nhằm đảm bảo an toàn lao động và đặc biệt quan tâm đẩy mạnh chương trình cơ giới hóa, tự động hóa, tin học hóa trong quản lý điều hành sản xuất để đảm bảo kiểm soát hoạt động sản xuất tại mọi nơi mọi lúc, nhằm phát hiện chấn chỉnh kịp thời tồn tại trong quá trình sản xuất, từ đó loại trừ các nguy cơ mất ATVSLĐ.

\section{Kết luận và kiến nghị}

Để đạt được mục tiêu đưa ngành công nghiệp khai thác khoáng sản của Việt Nam trở thành một ngành có trình độ công nghệ đạt trình độ khu vực, có đội ngũ cán bộ quản lý giỏi, đội ngũ công nhân lành nghề vào năm 2025 và hoạt động khai thác khoáng sản bảo đảm an toàn lao động, đạt tiêu chuẩn môi trường, bảo đảm quyền lợi người lao động; chấm dứt khai thác không tuân thủ thiết kế, không đảm bảo các điều kiện ATVSLĐ, lãng phí tài nguyên và hủy hoại môi trường và giảm $5 \%$ tần suất tai nạn lao động trong khai thác mỏ như mục tiêu Chương trình Quốc gia An toàn lao động, vệ sinh lao động giai đoaạ 2021 - 2025 đang được trình Thủ tướng Chính phủ phế duyệt, nhóm tác giả đề xuất một số giải pháp sau:

1. Các Bộ, Ngành, Tập đoàn, Tổng công ty tăng cường kiểm tra và chỉ đạo các đơn vị thuộc phạm vi quản lý thực hiện đầy đủ các quy định của Nhà nước về ATVSLĐ và các chế độ BHLĐ. Tăng cường đổi mới phương thức huấn luyện về ATVSLĐ cho người sử dụng lao động và người lao động .

2. Các địa phương cần tăng cường công tác thanh tra việc thực hiện các quy định của Nhà 
nước về ATVSLĐ ở các doanh nghiệp khai thác khoáng sản. Kiên quyết xử lý nghiêm minh, kịp thời đối với các hành vi vi phạm luật pháp lao động, đặc biệt công khai các doanh nghiệp không chấp hành nghiêm quy định pháp luật về ATVSLĐ.

3. Người sử dụng lao động trong các doanh nghiệp, cơ sở khai thác khoáng sản phải tuân thủ các quy định của nhà nước về ATVSLĐ. Tăng cường công tác tuyên truyền, phổ biến kiến thức về ATVSLĐ cho người lao động tại doanh nghiệp nhằm nâng cao nhận thức, ý thức tự giác phòng ngừa tai nạn lao động của người lao động.

4. Đảm bảo việc khai thác các loại khoáng sản phải được khảo sát, thăm dò và thiết kế khai thác đúng quy chuẩn, tiêu chuẩn quy định và phải được các cơ quan tổ chức có thẩm quyền phê duyệt; Các thiết kế thi công phải có các biện pháp an toàn cụ thể, chi tiết cho từng khai trường, khu vực sản xuất;

5. Tăng cường đào tạo, bồi dưỡng cho đội ngũ giám sát an toàn, quản đốc, phó quản đốc, trực ca về các kiến thức ATVSLĐ, đánh giá và phân tích rủi ro trong đào, chống lò và các biện pháp an toàn lao động mẫu cụ thể, chi tiết;

6. Áp dụng công nghệ tiên tiến đảm bảo an toàn và bảo vệ môi trường như thay việc phá vỡ đất đá bằng khoan - nổ mìn bằng máy xới làm tơi đất đá ờ những mỏ có điều kiện thích hợp; sử dụng công nghệ phá vỡ đá quá cỡ bằng búa đập thủy lực; loại bỏ công nghệ bốc xúc thủ công, triển khai vận tải bằng băng tải, đường ống;

7. Nâng cao năng lực hệ thống chăm sóc sức khỏe người lao động, phong chống bệnh nghề nghiệp từ TW đến địa phương; chăm sóc sức khỏe toàn diện cho người lao động trong tất cả các lĩnh vực; chăm sóc sức khỏe người lao động toàn diện từ dinh dưỡng hợp lý, vận động thể lực, đời sống tinh thần đến chất lượng cuộc sống...; đẩy mạnh điều trị thải độc, phục hồi chức năng nghề nghiệp cho người lao động mắc BNN; chăm sóc sức khỏe người lao động toàn diện từ khi mới bắt đầu đi làm, xuyên suốt quá trình làm việc và đến lúc nghỉ hưu;
8. Tăng cường công tác thanh tra, kiểm tra và xử lý nghiêm các vi phạm.

\section{Đóng góp của các tác giả}

Tác giả Nguyễn Anh Thơ hình thành ý tưởng, triển khai các nội dung và hoàn thiện bản thảo cuối của bài báo; tác giả Nguyễn Ngọc Bích gópý, chỉnh sửa, hoàn thiện phần thông tin tổng quan thế giới và đọc bản thảo bài báo.

\section{Tài liệu tham khảo}

B. M. Kunar., (2015). A Review on Occupational Health Hazards Associated with Surface Mining Operations. Conference proceeding. Challenges in Mining \& Mineral Industries (CMMI-2015), Keonjhar, September 26, 2015.

Bateman, C., (2014). Annually, 1\% of gold miners die-4\% sent home sick. SAMJ, 104, tr. 160-162.

Bộ Lao động - Thương binh và xã hội, (2019a). Báo cáo số 33/BC-LĐTBXH ngày 04/4/2019 của Bộ Lao động - Thương binh và Xã hội về tình hình thực hiện chính sách, pháp luật về an toàn, vệ sinh lao động giai đoạn 2016-2018.

Bộ Lao động - Thương binh và xã hội, (2019b). Thông báo số 1033/TB-LĐTBXH ngày 15/3/2019 của Bộ Lao động - Thương binh và Xã hội về tình hình TNLĐ năm 2018.

Bộ Y tế, (2018). Các bệnh nghề nghiệp thường gặp trong khai thác mỏ. Truy cập: https://moh.gov.vn/web/phong-chong-benhnghe-nghiep/thong-tin-hoat-dong/-

/asset_publisher/xjpQsFUZRw4q/content/ca c-benh-nghe-nghiep-thuong-gap-trong-khaithac--3. Ngày 19/8/2020

Chimamise C., Gombe NT., Tshimanga M., Chadambuka A., Shambira G., Chimusoro A., (2013). Factors associated with severe occupational injuries at mining company in Zimbabwe: A cross-sectional study. Pan African medical journal, 14(1), tr. 15-20. 
Jeyaratnam, J., (1992). Occupational Health in Developing Countries, Oxford University Press: New York, tr. 76.

Naidoo, RN., Robins, TG., Murray, J., (2005). Respiratory outcomes among South African coal miners at autopsy. Am J Ind Med , 48, tr. 217-224.

Nelson, G., Girdler-Brown, BV., Ndlovu, N., (2010). Three decades of silicosis: disease trends at autopsy in South African gold miners. Environ Health Perspect , 118(3), tr. 421-426.
Nowrouzi-Kia B., Gohar B., Casole J., Chidu C., Dumond J., McDougall A., Nowrouzi-Kia B., (2018). A systematic review of lost-time injuries in the global mining industry. Work, $60(1)$, tr. 49-61.

Yan Cui, Shuang-Shuang Tian,Nan Qiao, Cong Wang, Tong Wang, Jian-Jun Huang, Chen-Ming Sun, Jie Liang, Xiao-Meng Liu, (2015). Associations of Individual-Related and JobRelated Risk Factors with Nonfatal Occupational Injury in the Coal Workers of Shanxi Province: A Cross-Sectional Study. PLOS ONE, 10(7), tr. 184-192. 